\title{
MENCARI GAYA KEPEMIMPINAN YANG TEPAT UNTUK INDONESIA: PERSPEKTIF BUDAYA NASIONAL, KEPEMIMPINAN TRANSFORMASIONAL DAN KEPEMIMPINAN PATERNALISTIK
}

\author{
Dodi W. Irawanto \\ Program Magister Manajemen \\ Universitas Brawijaya
}

\begin{abstract}
Tidak dapat dipungkiri lagi bahwa meneropong budaya organisasi melalui Budaya Nasional (Globe studies) dapat memberikan dampak pada penerapan gaya kepemimpinan yang tepat dalam menuju efektivitas organisasi. Kepemimpinan transformasional sangat diharapkan dapat membawa organisasi untuk dapat mencapai performa yang unggul, sementara kepemimpinan dengan nilai lokal sedikit mendapatkan perhatian dari para peneliti kepemimpinan di Indonesia. Dengan mengurai dampak dari budaya nasional, artikel ini mencoba untuk menarik benang merah diantara dua model kepemimpinan, yakni kepemimpinan transformasional yang sangat berorientasikan nilai-nilia individualistik dan kepemimpinan paternalistik dengan penitikberatan pada nilia-nilai perilaku kolektivis; mana gaya kepemimpinan yang tepat untuk Indonesia.
\end{abstract}

Keywords:

Budaya nasional, transformasional, paternalistik, individualistik, kolektivist 


\section{PENDAHULUAN}

Globalisasi di era MEA serta masa yang akan datang membawa dampat pada perubahan yang sangat cepat di dalam lingkungan kehidupan berorganisasi. Dalam perkembangan dan perubahan itu akan mendorong persaingan antar organisasi di Indonesia baik itu organisasi nasional maupun multinasional, sehingga organisasi dituntut untuk berubah karena didorong oleh adanya persaingan yang semakin meningkat dan kompetitif.

Dalam situasi seperti ini diperlukan sosok pemimpin yang mampu melihat,menganalisis dan mendiagnosa perubahan lingkungan yang mempengaruhi organisasi (Camerron dan Quinn, 2005). Pemimpin sebagai pelopor perubahan harus mampu mengantisipasi perkembangan di dunia luar, serta menganalisis bagaimana mengatasi kompleksitas, ambiguitas, dan ketidak pastian yang ada dalam organisasi dengan dan mau bekerja keras dalam mengubah organisasi menjadi lebih baik dimasa depan pengaruh dan dampak kemajuan bagi organisasi (Zaccaro dan Klimoski, 2002).

Tidak dapat dipungkiri , Indonesia adalah negara dengan kebudayaan yang beraneka ragam dan bersifat kolektivis. Studi budaya nasional baik oleh Hofstede maupun Globe studies (Irawanto, 2007) mengindikasikan bahwa Indonesia mempunyai ciri berbudaya kolektivist dimana merupakan ramuan nilai-nilai (1) jarak kekuasaan yang tinggi; (2) penghindar dari ketidak pastian yang tinggi; (3) orientasi pada kekeluargaan serta hubungan manusia yang tinggi; dan (4) ketegasan yang rendah. Merupakan sebuah paradox dimana organisasi multinasional membutuhkan model kepemimpinan yang mampu mentransformasi organisasi (Fletcher, 2004) yang notabene di barat sering disebut sebagai kepemimpinan transformasi, akan tetapi 
beberapa studi menyatakan bahwa Indonesia membutuhkan kepemimpinan khusus yang sesuai dengan kebudayaan lokal yaitu kepemimpinan berorientasi pada nilai-nilai budaya lokal (Von Luebke, 2009).

Beberapa penelitian telah membuktikan bahwa model kepemimpinan transformasional di konteks budaya individualsits mampu membawa organisasi kepada kemajuan organisasi. Di lain sisi kepemimpinan paternalistik umumnya dipraktikkan dalam budaya kolektivis (Aafaqi et al., 2004; Aycan, 2006; Cheng et. al., 2004;Pellegerini dan Scandura, 2008; Westwood, 1997). Tentunya kepemimpinan paternalistik dapat di implementasikan di Indonesia yang notabene adalah negara dengan budaya kolektivis (Irawanto et al., 2012).

Hal ini biasa dilakukan pada sebuah organisasi atau perusahaan yang ditandai dengan penerapan hirarki yang tinggi, di mana tingkat formalisasi diharapkan terjadi dalam setiap lini manajemen dan pada setiap tingkat organisasi, dan di mana pentingnya menjaga hubungan timbal balik antara pemimpin dan karyawan dilegitimasi dalam perbatasan organisasi formal.

Menghadapi perubahan global menuntut organisasi untuk melakukan transformasi bisnis secara konsisten. Hal tersebut mengacu pada pendapat beberapa peneliti seperti (Harreld, et al, 2009; Kirkbride, 2006) yang mengungkapkan bahwa perubahan lingkungan dalam industri sangat cepat dan dinamis.

Hal yang sama seperti Indonesia yang membutuhkan gaya kepemimpinan yang khusus karena mempunyai budaya yang secara garis besar kolektivis Artikel ini bertujuan untuk mereview dalam konteks apa organisasi di Indonesia menuntu sebuah model kepemimpinan berbasis budaya lokal melalu kajian studi budaya nasional dan studi kepemimpinan kontemporer. 


\section{KAJIAN PUSTAKA}

Di dalam lingkungan ekonomi dan bisnis yang sangat berkembang di Indonesia untuk upaya menciptakan sistem dalam perusahaan yang kredibel dan akuntabel, perusahaan akan menetapkan sistem tata kelola yang responsif dan berorientasikan kepada nilai-nilai organisasi agar tercapai profesional kerja. Nilai-nilai keroganisasian merupakan refleski dari dari individu dalam organisasi yang secara tidak langsung sangat dipengaruhi oleh lingkungan budaya organisasi yang terbentuk (Lowendahl et al, 2001).

Dalam konteks budaya nasional, tidak dipungkiri lagi bahwa studi Hofstede merupakan studi menumental di dalam mendikotomi kan sebuah budaya yang dianut dari sebuah lingkungan sosial di sebuah negara (Tung dan Alain, 2010). Menurut studi Hofstede, budaya Indonesia dapat dikatagorikan sebagai budaya dengan ciri jarak kekuasaan, penghindar dari ketidapkastian, kolektivitas yang tinggi dan ketegasan serta maskulinitas yang rendah.

Studi kontemporer yang dilakukan oleh House et al. (2004) dalam proyek ambisius nya Globe Studies, menunjukkan konsistensi yang sama, yakni jarak kekuasaan, penhindar dari ketidakpastian, koletivitas institusi maupun sosial, orientasi pada hubungan manusia serta orientasi masa depan yang tinggi. Globe juga menandai bahwa kultur Indonesia rendah dalam memandang persamaan gender dan pentingnya pencapaian kinerja.

Beberapa studi terakhir yang dilakukan oleh Irawanto (2012); Handayani et al. (2014) juga menunjukkan konsistensi yang sama, ini menandakan walaupun kultur professional sudah dikenalkan dalam berkehidupan berorganisasi, namun karyawan Indonesian pada umumnya masih menjunjung tinggi nilia-nilai budaya seperti yang ditunjukkan dari dua studi monumental 
tersebut. Tidak dapat dipungkiri nilai-nilai individu dalam berorganisasi sangat menjunjung tinggi konsep budaya serta agama yang sangat dijunjung tinggi di Indonesia (Purhantara, 2010).

Satu-satunya studi internasional tentang penggolongan kepemimpinan yang disandarkan pada budaya nasional adalah studi yang dilakukan oleh House et al. (2004) dalam Globe Studies nya. Secara garis besar kepemimpinan yang dipreferensikan oleh karyawan di Indonesia adalah (dari yang paling penting):

a.Memandang pentingnya nilai-nilai karismatik dari seorang pemimpin.

Ciri-ciri pemimpin karismatik menurut studi ini adalah menjunjung tinggi nilainilai moral serta etika dan selalu berada di depan demi membela yang benar.

b.Memandang pentingnya berorientasi pada bekerja dalam tim.

Ciri-ciri pemimpin berorientasi pada kerja tim adalah mengedepankan koordinasi pekerjaan berdasarkan pada pertimbanganpertimbangan kolegial dan secara diplomatis menyelesaikan permasalahan.

c.Memandang pentingnya nilai-nilai partisipatif.

Ciri-ciri pengedepanan nilai nilia partisipatif ditunjukkan pemimpin dalah upaya konsultasi dalam pengambilan keputusan untuk mendapatkan konsensus kolektif.

d.Memandang pentingnya nilai-nilai orientasi pada manusia.

Ciri-ciri penanaman nilai oreintasi pada manusia ditunjukkan oleh pemimpin berupa memperhatikan orang lain, toleransi serta memberi dukungan tidak saja kepada karyawan akan tetapi keluarganya juga.

Dapat dilihat bahwa kekonsistensian nilai-nilai kepimpinan utama yang disimpulkan oleh studi Globe sangat beralasan. Budaya nasional merupakan akar dari perilaku kepemimpinan. Kepemimpinan 
karismatik dan partisipatif sangat didasarkan pada pengedepanan kepentingan kolektivis, demikian pula nilai-nilai orientasi kerja pada tim dimana didasarkan pada fakta bahwa budaya nasional Indonesia sangatlah rendah dalam penghindaran dari ketidakpastian. Kecenderungan pemimpin berlaku dengan pengedepanan oreintasi pada manusia didasarkan pada fakta bahwa Indonesia menjunjung tinggi nilai hubungan pada sesama (Gupta, et al, 2002).

Gaya kepemimpinan yang tepat dalam sebuah perusahaan akan meningkatkan kinerja pegawai dan memaksimalkan potensi sumber daya manusia (Yukl, 2008) dalam organisasi yang besar, efektivitas seorang pemimpin tergantung pada kekuatan pengaruh gaya kepemimpinan terhadap atasan, rekan sejawat, dan pengaruhnya terhadap bawahannya.

Gaya kepemimpinan merupakan aspek penting untuk mencapai dan meningkatkan keberhasilan kepemimpinan seseorang dalam suatu organisasi. Dalam era globalisasi dibutuhkan model kepemimpinan yang tidak biasa (Kouzes dan Posner, 2006). Penelitian di negara negara maju mengindikasikan bahwa gaya kepemimpinan transformasional merupakan penyeimbang yang ideal dalam upaya organisasi mentransformasi bisnisnya .Avolio dan Bass (1995) berpendapat ada empat hal yang menjadi ciri pemimpin transformasional, yakni:

a.Pengaruh yang diidealkan (idealized influence) adalah sifat-sifat keteladanan yang ditunjukkan kepada pengikut dan sifat-sifat yang dikagumi pengikut dari pimpinannya.

b.Stimulasi intelektual (intelectual stimulation). Dalam menunjukkan aspek ini, pemimpin mengajak pengikutnya untuk selalu mempertanyakan asumsi di balik suatu hal, mencari cara baru dalam mengerjakan sesuatu hal. 
c. Kepedulian secara perorangan (individual consideration) adalah ciri pemimpin yang memperhatikan kebutuhan karaywannya dan membantu karyawan agar mereka bisa maju dan berkembang dalm karier dan kehidupan mereka.

d.Motivasi yang inspirasional (inspirational motivation) adalah sifat pemimpin yang memberikan inspirasi dlam bekerja, mengajak karyawan untuk mewujudkan sebuah cita-cita bersama agar hidup dan karya mereka menjadi bermakna.

Salah satu prasayarat penerapan kepemimpinan transformasional adalah kematangan berpikir karyawan, ditandai berupa dedikasi professional, komitment karyawan terhadap organisasi yang kuat serta keadaaan lingkungan kerja yang ter empowered (Avolio, et al, 2004). Sangat logis karena dari empat dimensi kepempimpinan transformasional sangatlah jelas jika pemimpin sudah merasa yakin bahwa bawahan pada dasarnya "sudah mampu", yang dalam konteks mereka (baca individualis) ini sudah terbentuk sejak karyawan dididik di lingkungan keluarga, dan sekolah dimana penekanan untuk menjadi mandiri dan self discipline adalah menjadi oreintasi dari sebagian besar individu dari kultur ini (Leithwood et al, 2008).

Kepemimpinan transformasional menjadi model kepemimpinan yang tepat bagi sebagian besar organisasi dengan kultur individu yang individualistik, dan sangat sedikit fakta bahwa kepemimpinan transformasional mampu memberikan dampak positif terhadap kinera organisasi di budaya kolektifist (Jung dan Avolio, 1999; Muenjohn dan Armstrong, 2015). Selama ini banyak sekali penelitian tentang kepemimpinan transformasional seakan-akan kepemimpinan ini menjadi gaya kepemimpinan yang sangat sukses dan berhasil dalam segala situasi dan kondisi di masa sekarang. Namun kebanyakan 
penelitian transformasional di lakukan di negara barat yang merupakan negara-negara mengusung individualisme seperti penelitian yang dilakukan oleh Jung D, et all (2002) dan Jogulu (2010). Transformasional leadership dipertanyakan ke universalannya, apakah ini dapat diterapkan di konteks budaya non western (Leong dan Fischer, 2011).

Adalah Cheng et al. (2004) yang mencoba menchallange aplikabilitas kepemimpinan dengan nilai-nilai kebaratan (baca:individualistis) di konteks budaya kolektifis. Cheng telah melakukan beberapa studi di budaya kolektifis dengan akar budaya confucian (negara-negara dengan sebaran budaya China) dan menemukan bahwa kepemimpinan paternalistik merupana sebuah model yang dapat diterima di era globalisasi ini, dan menolak kepemimpinan transformasional.

Kepemimpinan paternalistik sangat cocok untuk diterapkan di Indonesia karena budaya Indonesia yang tidak mengusung individualisme melainkan koletivisme serta secara historis budaya Indonesia juga diwarna oleh budaya confucian.). Karena perbedaan situasi manajemen, transformasional dan teori kepemimpinan transaksional lazim dalam budaya barat namun belum tentu cocok untuk perusahaan dalam budaya Timur. Perusahaan Cina di daratan Cina, Hong Kong, Taiwan, Indonesia, dan Singapura menempatkan kepemimpinan paternalistik sebagai model kepemimpinan yang dapat diterima dan terbukti memberikan dampak positif terhadap kinerja organisasi (Liden , 2012).

Beberapa penelitian telah menetapkan bahwa kepemimpinan paternalistik umumnya dipraktikkan dalam budaya kolektivis. Tentunya kepemimpinan paternalistik dapat di implementasikan di Indonesia yang notabene adalah negara dengan budaya kolektivis. Hal ini biasa dilakukan pada sebuah organisasi atau 
perusahaan yang ditandai dengan birokrasi yang tinggi, di mana tingkat formalisasi diharapkan terjadi dalam setiap aspek dan pada setiap tingkat organisasi, dan di mana pentingnya menjaga hubungan timbal balik antara pemimpin dan pegawai dilegitimasi dalam perbatasan organisasi forma (Ellis, 2011).

Penelitian tentang kepemimpinan paternalistik di Taiwan, yang dilakukan oleh Bor-Shiuan Cheng dan rekan-rekannya (Pellegrini dan Scandura, 2008) dan berbasis pada nilai-nilai budaya yang terkait dengan masyarakat Cina. Banyak peneliti melakukan penelitian yang sama karena kesamaan mereka dengan masyarakat Cina, etnis lain di Asia Tenggara akan responsif terhadap kepemimpinan paternalistik: seperti halnya di Indonesia (Irawanto, 2008), Malaysia (Ansari et al., 2004) dan Filipina (Restubog dan Bordia, 2008). Jika kepemimpinan paternalistik memberikan dampak positif terhadap aspek psikologi pegawai dalam menjalankan tugasnya apakah juga akan memberikan jaminan terhadap tercapainya inovasi manajemen dalam tata kelola yang kredibel dan akuntabel.

Kepemimpinan paternalistik secara historis adalah gaya manajemen yang lazim dalam bisnis kapitalistik awal (Wren, 2005). Kepemimpinan paternalistik sebagai spesifik untuk budaya Cina dimulai dengan studi kualitatif Silin (1976) tentang perilaku kepemimpinan para pemilik dan manajer bisnis di perusahaan besar di Taiwan.

Silin (1976) menemukan bahwa perilaku kepemimpinan dalam organisasi yang sangat berbeda dari apa yang biasanya diamati dalam organisasi Barat. Manajer ini bersikap direktif, memegang otoritas terpusat, dilaksanakan dengan taktik kontrol implisit, dan memelihara jarak sosial dari bawahan. Kesimpulan Silin telah melahirkan landasan konseptual untuk kepemimpinan paternalistik di Cina. Kepemimpinan paternalistik secara eksplisit dilakukan untuk 
gaya manajemen di Cina berasal dari penelitian Redding (1990).

Tiga dimensi kepemimpinan paternalistik, seperti yang diusulkan oleh Farh dan Cheng (2000), adalah otoritarianisme, kebajikan, dan moralitas. Studi di Indonesia yang dilakukan oleh Irawanto et al. (2012) mengkatagorikan kepemimpinan paternalistik menjadi tiga domain utama, yakni:

a. Kepemimpinan Visibel; Seorang pemimpin harus selau tampil di depan dan selalu ada saat dibutuhkan oleh bawahananya.

b.Kepemimpinan Otoriter; Seorang pemimpin harus mempunyai kemampuan mendireksi yang tinggi dengan pengedepanan penerapan nilai-nilai disiplin yang tinggi.

c. Kepemimpinan Kebajikan; Seorang pemimpin harus mempunyai kehangatan jiwa yang dapat direfleksikan dalam perilaku bijak terhadap sesama.
d.Kepemimpinan Moral

- Kepemimpinan Moral Tidak Korupsi; Seorang pemimpin harus bertindak profesional dan tidak mengedepankan kepentingan pribadi maupun golongan.

- Kepemimpinan Moral Bertindak Adil; Seorang pemimpin harus menjunjung tinggi kebenaran dan bertindak adil kepada bawahannya.

- Kepemimpinan Moral dengan Keberanian; Seorang pemimpin harus mengedepankan prinsip kebenaran.

- Kepemimpinan Moral Murah hati; Seorang pemimpin mampu mengedepankan toleransi dan terbuka terhadap pendapat orang lain.

Dapat dilihat bahwa secara kasat mata tujuh dimensi kepemimpinan paternalistik disini mempunyai penekanan pada nilia-nilai kolektivitis yang tinggi, dimana keterbutuhan pemimpin yang mampu berada di depan serta menkomandani segala aspek kehidupan berorganisasi baik itu 
dalam kemasan formalitas organisasi maupun di luar organisasi menjadi bagian dari keseharian kepemimpinan Paternalistik.

\section{PEMBAHASAN DAN KESIMPULAN}

Telah diurai di atas bagaimana indikator budaya nasional melalui teropong dimensi budaya nasional Hofstede dan Globe Studies, mengindikasikan bahwa budaya nasional Indonesia mewarnai perilaku karyawan di organisasi di Indonesia. Terlebih studi Globe mampu merangkum beberapa dimensi kepemimpinan universal yang mewarnai model kepemimpinan yang dipreferensikan oleh karyawan di Indonesia. Dapat di simpulkan bahwa budaya nasional menjadi acuan utama dari sebuah organisasi untuk menentukan pola kepemimpinan yang nantinya tepat untuk diterapkan demi efektifiitas organisasi.
Kepemimpinan transformasional menawarkan model kepemimpinan yang berlandaskan pada "kekuatan" karyawan dimana ini merupakan bentukan dari kultur individualistik, sehingga peran pemimpin menjadi "pendorong" dari kekuatan yang sudah ada untuk mencapai performa organisasi yang lebih baik (Avolio dan Hannah, 2008). . Dengan dasar ini diharapkan organisasi mampu mengoptimalkan potensi karyawan yang ada dan menjadi pendorong otomatis bagi karyawan untuk selalu termotivasi memberikan kinerja terbaik mereka.

Di lain sisi kepemimpinan paternalistik menawarkan model kepemimpinan yang memberikan nuansa budaya lokal dengan pengedepanan peran sentral pemimpin sebagai father figure dimana pemastian peran pemimpin di dalam segala lini manajemen menjadi penting. Terlebih dengan ramuan campuran kepemimpinan otoriter, kebajikan dan moral 
dapat menjadi role model yang baik bagi karyawan sehingga mereka terpastikan kebutuhan non material nya sehingga dapat diperoleh kultur karyawan yang sigap dan mau untuk melakukan segala perintah pimpinan (Hernandez, et al, 2011).

Dengan melihat pada akar budaya Indonesia serta budaya nasional yang sudah disajikan dalam kaian pustaka diatas, sepertinya model kepimimpinan paternalistik dapat diterima oleh sebagian besar organisasi di Indonesia, terutama organisasi dengan kultur birokrasi dan hirarki yang masih sangat kental (misal organisasi publik/pemerintahan, BUMN dan organisasi swasta yang masih minim sentuhan asing nya). Asumsi ini menjadi logis karena kultur lunak bawahan sejatinya sudah terbentuk sejak awal sehingga peran pemimpin hanya dalam kapasitas "memastikan" bahwa bawahan mampu melakukan kinerja nya secara optimal.
Di Indonesia tidak semua organisasi mempunyai kultur akselerasi kenerja yang baik. Sebagian besar kultur organisasi di Indonesian adalah berbentuk patrimoni yakni peran pemimpin di organisasi tidak terbatas pada peran formal saja akan tetapi sampai menyentuh ke sendi-sendi kehidupan organisasi (Kirk dan Starn, 2009) . Ini menjadi ruang bagi model kepemimpian paternalistik untuk diterapakn dalam kultur organisasi semacam ini.

Di lain sisi, organisasi besar swasta, perusahaan multi nasional dan BUMN yang sudah bertransforamsi dengan budaya akselarasi tinggi dimana ada tuntutan untuk menjadi organisasi kelas dunia, tuntutan penerapan model kepemimpinan transformasional mungkin menjadi logis untuk diterapkan. Tentu penerapan model kepemimpinan yang berdasarkan pada budaya individualistis membutuhkan sentuhan modifikasi sehingga tidak 
mempunyai potensi untuk merusak tatanan kultur organisasi yang sudah ada.

Artikel ini memberikan wawasan dalam konteks budaya nasional, serta dua model kepemimpinan yang seyogyanya dalam penerapan nya perlu analisis yang mendalam. Sesuai dengan tujuan dari artikel ini, di dalam upaya memajukan organisasi yang ada di Indonesia, gaya kepemimpinan apakah yang tepat untuk diimplementasikan di Indonesia, ini semua kembali ke konteks di mana bentukan kultur dari organisasi itu sendiri, tidak hanya dari segi pemimpin nya saja akan tetapi perlu adanya analisa mendalam pada kultur bawahan juga. 


\section{DAFTAR PUSTAKA}

Aafaqi, R. 2004. "Organizational leadership in the Malaysian context". Leading in high growth Asia: Managing relationship for teamwork and change, 109.

Avolio, B. J., \& Bass, B. M. 1995.” Individual consideration viewed at multiple levels of analysis: A multilevel framework for examining the diffusion of transformational leadership". The Leadership Quarterly, 6(2), 199-218.

Avolio, B. J., Zhu, W., Koh, W., \& Bhatia, P. 2004. "Transformational leadership and organizational commitment: Mediating role of psychological empowerment and moderating role of structural distance". Journal of organizational behavior, 25(8), 951-968.

Avolio, B. J., \& Hannah, S. T. 2008. "Developmental readiness: Accelerating leader development". Consulting Psychology Journal: Practice and Research, 60(4), 331.

Aycan, Zeynep. 2006. "Paternalism." Indigenous and cultural psychology, pp. 445-466. Springer US,

Cameron, K. S., \& Quinn, R. E. 2005. Diagnosing and changing organizational culture: Based on the competing values framework. John Wiley \& Sons.

Cheng, B. S., Chou, L. F., Wu, T. Y., Huang, M. P., \& Farh, J. L. 2004. "Paternalistic leadership and subordinate responses: Establishing a leadership model in Chinese organizations”. Asian Journal of Social Psychology, 7(1), 89-117.

Ellis, K. 2011. 'Street-level Bureaucracy'Revisited: The Changing Face of Frontline Discretion in Adult Social Care in England". Social Policy \& Administration, 45(3), 221-244.

Fletcher, J. K. 2004. "The paradox of postheroic leadership: An essay on gender, power, and transformational change". The leadership quarterly, 15(5), 647-661.

Gupta, V., Surie, G., Javidan, M., \& Chhokar, J. 2002. "Southern Asia cluster: where the old meets the new?". Journal of world business, 37(1), 16-27.

Harreld, J. B., O'Reilly, C. A., \& Tushman, M. L. 2007. "Dynamic capabilities at IBM: Driving strategy into action". California Management Review, 49(4), 21-43.

Hernandez, M., Eberly, M. B., Avolio, B. J., \& Johnson, M. D. 2011. "The loci and mechanisms of leadership: Exploring a more comprehensive view of leadership theory”. The Leadership Quarterly, 22(6), 1165-1185.

House, R. J., Hanges, P. J., Javidan, M., Dorfman, P. W., \& Gupta, V. (Eds.). 2004. Culture, leadership, and organizations: The GLOBE study of 62 societies. Sage publications.

Irawanto, D. 2007. "National culture and leadership: Lesson from Indonesia". Journal of Business and Management Eksekutif, 4(3), 359-367.

Irawanto, D. W., Ramsey, P. L., \& Tweed, D. C. 2012. "Exploring paternalistic leadership and its application to the Indonesian public sector". International Journal of Leadership in Public Services, 8(1), 4-20.

Jogulu, U. D. 2010. “Culturally-linked leadership styles”. Leadership \& Organization Development Journal, 31(8), 705-719.

Jung, D. I., \& Avolio, B. J. 1999. "Effects of leadership style and followers' cultural orientation on performance in group and individual task conditions". Academy of management journal, 42(2), 208-218.

Jung, D., Yammarino, F. J., \& Lee, J. K. 2009. "Moderating role of subordinates' attitudes on transformational leadership and effectiveness: A multi-cultural and multi-level perspective". The Leadership Quarterly, 20(4), 586-603.

Kirkbride, P. 2006. "Developing transformational leaders: the full range leadership model in action". Industrial and commercial training, 38(1), 23-32.

Kirk, R., \& Starn, O. 2009. The Indonesia reader: History, culture, politics. T. Hellwig, \& E. Tagliacozzo (Eds.). Duke University Press.

Kouzes, J. M., \& Posner, B. Z. 2006. The leadership challenge (Vol. 3). John Wiley \& Sons. 
Leithwood, K., Harris, A., \& Hopkins, D. 2008. "Seven strong claims about successful school leadership". School leadership and management, 28(1), 27-42.

Leong, L. Y. C., \& Fischer, R. 2011. "Is transformational leadership universal? A meta-analytical investigation of multifactor leadership questionnaire means across cultures". Journal of Leadership \& Organizational Studies, 18(2), 164-174.

Liden, R. C. 2012. "Leadership research in Asia: A brief assessment and suggestions for the future". Asia Pacific Journal of Management, 29(2), 205-212.

Løwendahl, B. R., Revang, Ø., \& Fosstenløkken, S. M. 2001. "Knowledge and value creation in professional service firms: A framework for analysis". Human relations, 54(7), 911-931.

Muenjohn, N., \& Armstrong, A. 2015. "Transformational leadership: The influence of culture on the leadership behaviours of expatriate managers". international Journal of Business and information, 2(2).

Pellegrini, E. K., \& Scandura, T. A. 2008. "Paternalistic leadership: A review and agenda for future research". Journal of management, 34(3), 566-593.

Purhantara, W. 2010. "Kepemimpinan Bisnis Indonesia di Era Pasar Bebas". Jurnal Ekonomi \& Pendidikan, $7(1)$.

Restubog, S. L. D., \& Bordia, P. 2008. "One big happy family: Understanding the role of workplace familism in the psychological contract dynamics". Advances in organisational psychology, 371.

Tung, R. L., \& Verbeke, A. 2010. "Beyond Hofstede and GLOBE: Improving the quality of cross-cultural research". Journal of International Business Studies, 41(8), 1259-1274.

Von Luebke, C. 2009. "The political economy of local governance: findings from an Indonesian field study". Bulletin of Indonesian Economic Studies, 45(2), 201-230.

Westwood, R. 1997. "Harmony and patriarchy: The cultural basis for'paternalistic headship'among the overseas Chinese". Organization studies, 18(3), 445-480.

Yukl, G. 2008. "How leaders influence organizational effectiveness". The leadership quarterly, 19(6), 708722.

Zaccaro, S. J., \& Klimoski, R. J. (Eds.). 2002. The nature of organizational leadership: Understanding the performance imperatives confronting today's leaders (Vol. 12). John Wiley \& Sons. 